\title{
Differential Absorption Analysis of Nonmagnetic Material in the Phantom using Dual CT
}

\author{
Ki-Youl Kim', Hae-Kag Lee ${ }^{2}$, and Jae-Hwan $\mathrm{Cho}^{3 *}$ \\ ${ }^{1}$ Department of Radiology, Kyung Hee University Hospital at Gang-dong, Seoul 05278, Korea \\ ${ }^{2}$ Department of Computer Science and Engineering, Soonchunhyang University, Asan 31538, Korea \\ ${ }^{3}$ Department of Radiological Technology, Ansan Univerity, Ansan 15518, Korea
}

(Received 8 March 2016, Received in final form 25 March 2016, Accepted 4 April 2016)

\begin{abstract}
This study evaluates the change of computer tomography (CT) number in the case of the metal artifact reduction (MAR) algorithm, using the phantom. The images were obtained from dual CT using a gammex 467 tissue characterization phantom, which is similar to human tissues. The test method was performed by dividing pre and post MAR algorithm and measured CT values of nonmagnetic materials within the phantom. In addition, the changes of $\mathrm{CT}$ values for each material were compared and analyzed after measuring $\mathrm{CT}$ values up to $140 \mathrm{keV}$, using the spectral HU curve followed by CT scan. As a result, in the cases of N rod (trabecular bone) and $\mathrm{E}$ rod (trabecular bone), the $\mathrm{CT}$ numbers decreased as $\mathrm{keV}$ increasing but were constant above 90 $\mathrm{keV}$. In the cases of $\mathrm{I}$ rod (dense bone) and $\mathrm{K}$ rod (dense bone), the $\mathrm{CT}$ numbers also decreased as keV increased but were uniform above $90 \mathrm{keV}$. The CT numbers from $40 \mathrm{keV}$ to $140 \mathrm{keV}$ were consistent in the cases of $\mathbf{J}$ rod (liver), D rod (liver), $\mathrm{L}$ rod (muscle), and F rod (muscle). For A rod (adipose), G rod (adipose), B rod (breast) and $O$ rod (breast), the $C T$ numbers increased as $\mathrm{keV}$ increased but were constant after $90 \mathrm{keV}$. The CT numbers from $40 \mathrm{keV}$ to $140 \mathrm{keV}$ were consistent in the cases of $\mathrm{C}$ rod (lung (exhale)), $P$ rod (lung (exhale)), $M$ rod (lung (inhale)) and $\mathrm{H}$ rod (lung (exhale)). Conclusively, because dual CT exhibits no changes in image quality and is able to analyze nonmagnetic materials by measuring the $\mathrm{CT}$ values of various materials, it will be used in the future as a useful tool for the diagnosis of lesions.
\end{abstract}

Keywords : MAR algorithm, nonmagnetic material, dual CT, CT number

\section{Introduction}

Since the introduction of medical imaging systems, computed tomography (CT) has rapidly developed in its technical performance and clinical applications. The test speed and the image quality were improved by spiral CT and other inspection equipment especially able to measure sub-seconds of testing time with multi-detection ability as the new generation system. To describe the image theory of CT simply, an X-ray generated from an X-ray tube penetrates a certain material, and the differential absorptions by radiolucent and radiopaque actions is described on a monitor as various types of black and white. In other words, this theory is explained as an X-ray being turned into an image on a screen by differential attenuation. The attenuation of the X-ray means that its intensity is

CThe Korean Magnetics Society. All rights reserved.

*Corresponding author: Tel: +82-31-400-6942

Fax: +82-31-400-6941, e-mail: 8452404@hanmail.net decreased by absorbing or scattering in the process of Xray transmission. It is based on the Lambert-Beer Law which expresses photon changes as an exponential relationship according to the tissue penetration when an X-ray permeates the tissue. The parameters that influence the attenuation in CT are X-ray photon energy like general Xray, tissue density, the atomic number of the tissue, and material electrons per unit weight [1]. The formation of an X-ray image is made up from information about attenuated photons while the X-ray penetrates the patient. If all the X-ray photons were to penetrate the patient, the screen image would be entirely black. If all the X-ray photons were to be attenuated, the image would be white. Therefore, the image contrast is decided by the differential attenuation among human tissues. CT expresses the distribution of this attenuation coefficient as the CT number [1]. The line attenuation coefficient is affected by several factors, including radiation energy. For example, the line attenuation coefficient of water indicates differences of $0.206 \mathrm{~cm}^{-1}$ in $60 \mathrm{keV}, 0.19 \mathrm{~cm}^{-1}$ in $73 \mathrm{keV}$, 
$0.180 \mathrm{~cm}^{-1}$ in $84 \mathrm{keV}$, and $0.166 \mathrm{~cm}^{-1}$ in $122 \mathrm{keV}$. So, because the CT number can be calculated by the attenuation coefficient, this means that the photon energy also affects the CT number [1]. In addition, if a metal is inserted into a CT image, the metal artifact is generated and may cause changes in the CT number and photon density, so it can also influence the CT number [2-4]. The generation of high-density artifacts in CT images is primarily caused by missing projection data. The following methods which have been studied up to now are available for algorithms to decrease the metal artifact: filtered back projection with linear interpolation, iterative deblurring, and wavelet [5-10]. However, the suggested algorithms require long calculation times to reconstitute the final image, so there are difficulties in using them at this moment. Furthermore, because these algorithms primarily focus on removing the streak artifact, they have the limitation that a metal artifact generated around metal implants or inserts cannot be removed [11]. A metal artifact reduction (MAR) algorithm was recently developed [12]. According to the gemstone spectra image (GSI), recently developed in $\mathrm{S}$ company it facilitates the analysis of a material by realizing the image with various energies from $40 \mathrm{keV}$ to $140 \mathrm{keV}$ using a monochromatic radiation having homogenous flux after the CT scan. This study estimates the change of CT number by using the MAR algorithm with a phantom.

\section{Subjects and Methods}

\subsection{Equipment and phantom}

A Discovery CT750 HD (GE Healthcare, Wisconsin, USA) that rapidly crosses two energies (80 kVp and 140 $\mathrm{kVp}$ ) and irradiates X-rays was used as the CT equipment

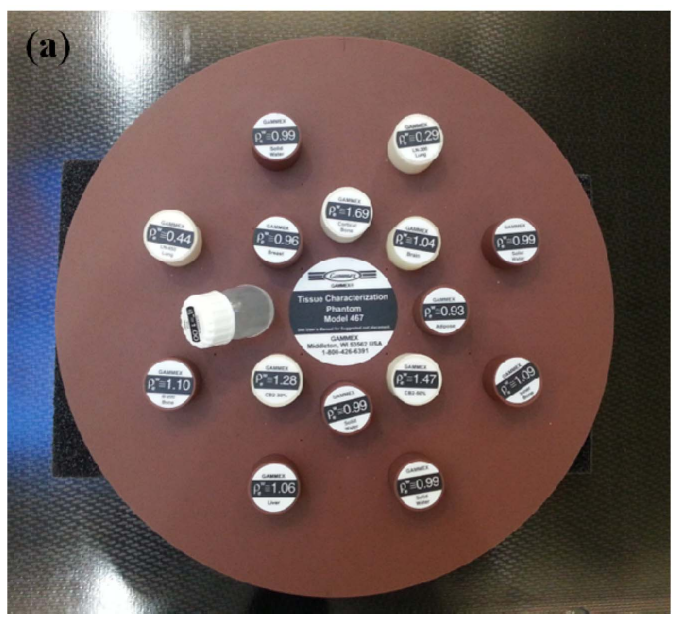

for the phantom study, and an AW 4.5 Volume Share 4 (GE Healthcare) was used for imaging analysis. The images were obtained from a Gammex 467 Tissue Characterization Phantom (TomoTherapy Inc., Madison, WI), which is similar to human tissues (Fig. 1).

\subsection{Method}

The test was conducted by dividing before and after MAR algorithms under the same scanning condition. The scanning conditions for the phantom study were set with parameters for a general brain scan as follows: $120 \mathrm{kVp}$ for tube voltages, 100-350 $\mathrm{mA}$ (smart $\mathrm{mA}$, noise index: 22.1) for tube currents, standard reconstruction, $40 \mathrm{~mm}$ detector coverage, $0.625 \mathrm{~mm}$ helical thickness, helical

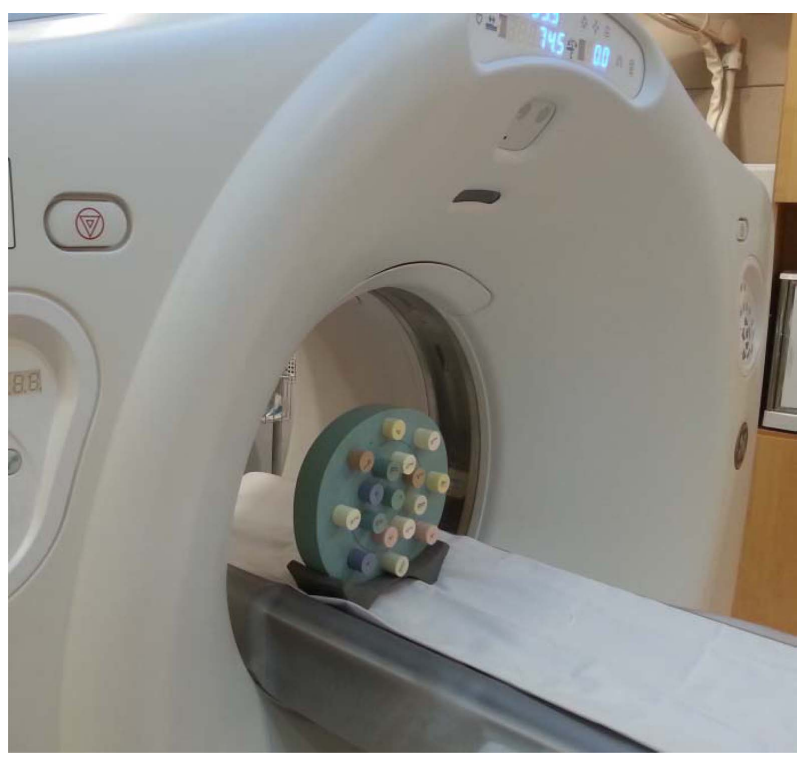

Fig. 2. (Color online) Gammex 467 tissue characterization phantom was scanned using dual CT.

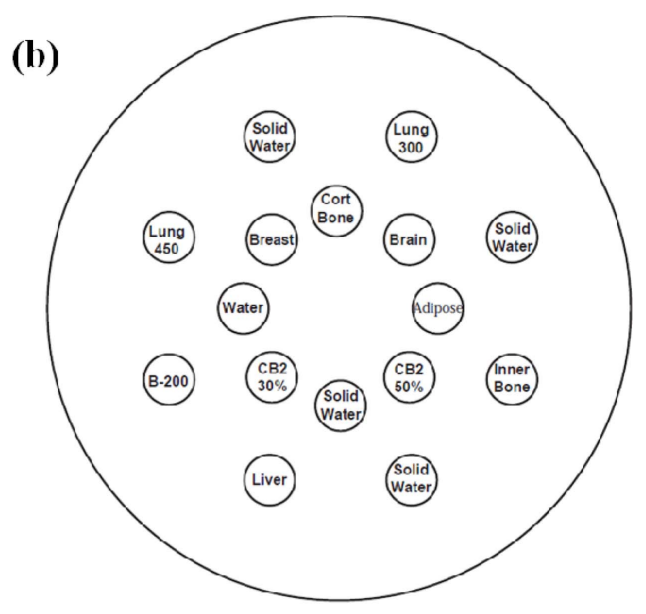

Fig. 1. (Color online) Gammex 467 tissue characterization phantom, which is similar to human tissues (a). Fig b is the cross section image of the phantom. 

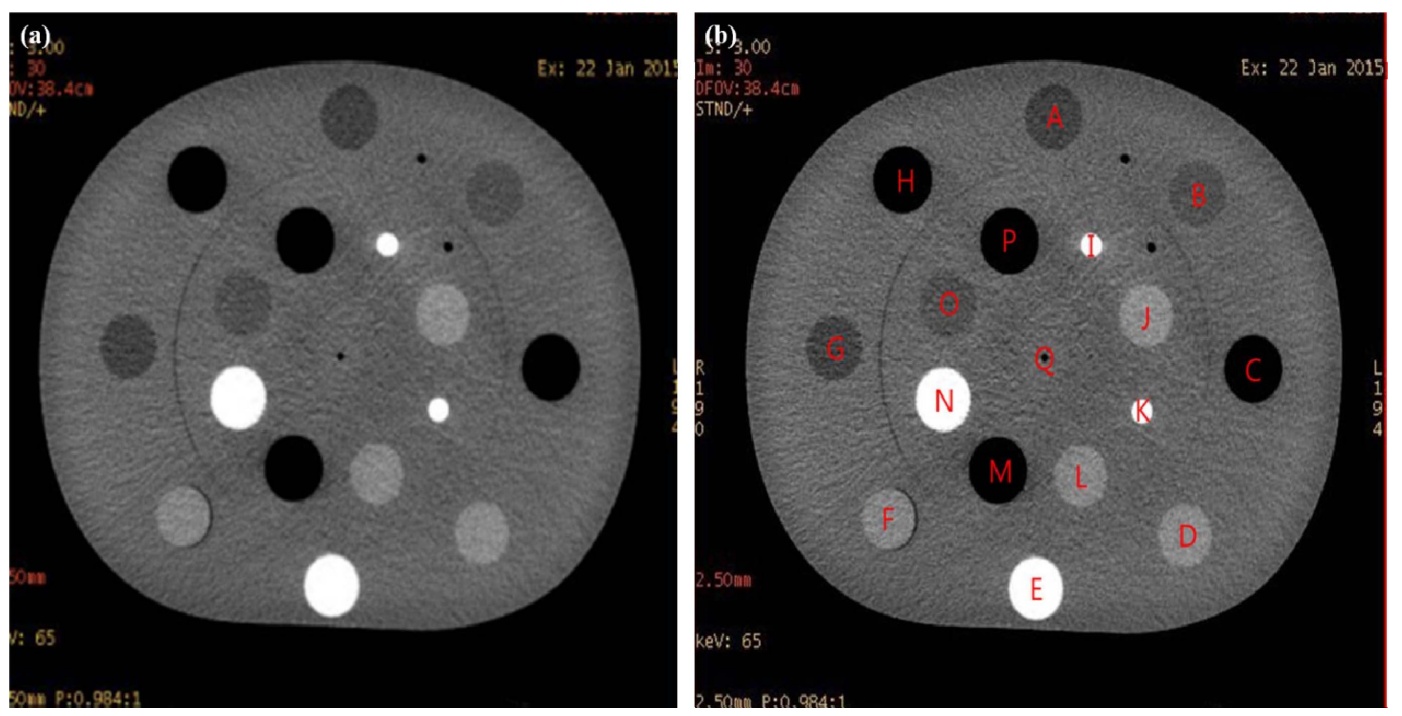

Fig. 3. (Color online) (a) is the scanned image of Gammex 467 tissue characterization phantom using dual CT and (b) indicates 16 rods setting in the same size of interesting area.

mode for scan type, and 0.6 seconds of rotation time. The coverage speed was $65.62 \mathrm{~mm} / \mathrm{sec}$ and pitch/speed was 0.984:1 (39.37 $\mathrm{mm} / \mathrm{rot})$. Tube voltage and current were scanned by the modulation of equipment in the case of GSI mode scanning (Fig. 2). The mean value was recorded by calculating CT values a total of 20 times after the obtained images for measuring and analyzing CT values within a phantom were transferred to AW 4.5 Volume Share 4, and then the area of interest was set as the same size of 16 rods diameter. In the case of 16 rods, the A rod is for adipose, B rod for breast, $\mathrm{C}$ rod for lung (exhale), D rod for liver, E rod for trabecular bone, F rod for muscle, $\mathrm{G}$ rod for adipose, $\mathrm{H}$ rod for lung (exhale), I rod for dense bone, $\mathrm{J}$ rod for liver, $\mathrm{K}$ rod for dense bone, $\mathrm{L}$ rod for muscle, $\mathrm{M}$ rod for lung (inhale), $\mathrm{N}$ rod for trabecular bone, O rod for breast, $\mathrm{P}$ rod for lung (exhale), and Q rod for water. The diameter of rod is $10 \mathrm{~mm}$ (Fig. 3). In addition, the changes of $\mathrm{CT}$ values for each material were compared and analyzed after measuring CT value up to $140 \mathrm{keV}$, using the spectral HU curve followed by CT scan. The average analysis of CT number and noise with or without the MAR algorithm was carried out using the SPSS Statistics (version 17, USA, Chicago) program, and its statistical significance was estimated by the paired sample t-test.

\section{Results}

Table 1 shows the CT numbers before and after using the MAR algorithm for each material. For A rod (adipose), it was $64.34 \pm 20.45 \mathrm{HU}$ before using the MAR algorithm and $-66.84 \pm 8.55 \mathrm{HU}$ after using it in $60 \mathrm{keV}$. It was measured at about $-41.82 \pm 19.40 \mathrm{HU}$ before using and $-43.09 \pm 17.17 \mathrm{HU}$ after using in $80 \mathrm{keV}$. Conclusively, A rod (adipose) indicated that the CT numbers were reduced more after using the MAR algorithm than before using it, and its noise was decreased as well $(\mathrm{p}<$ $0.05)$. In the case of B rod (breast), the CT number was measured as $-39.92 \pm 17.79 \mathrm{HU}$ before using the MAR algorithm and $-39.72 \pm 18.74 \mathrm{HU}$ after using it in $60 \mathrm{keV}$. It was also $-26.50 \pm 17.55 \mathrm{HU}$ before using and $-26.69 \pm$ $18.10 \mathrm{HU}$ after using in $80 \mathrm{keV}$. There was no significant difference statistically ( $p>0.05$ ). For $\mathrm{C}$ rod (lung (exhale)), the CT number was measured as $-461.44 \pm 95.19 \mathrm{HU}$ before using the MAR algorithm and $-478.51 \pm 45.58$ $\mathrm{HU}$ after using it in $60 \mathrm{keV}$. It was also $-465.90 \pm 93.72$ $\mathrm{HU}$ before using and $-482.26 \pm 47.27 \mathrm{HU}$ after using in $80 \mathrm{keV}$. Conclusively, C rod (lung (exhale)) represented that the CT numbers were reduced more after using the MAR algorithm than before using, and its noise was was decreased as well $(p<0.05)$. In the case of D rod (liver), the CT number was measured as $51.34 \pm 23.82 \mathrm{HU}$ before using the MAR algorithm and $-51.92 \pm 26.83 \mathrm{HU}$ after using it in $60 \mathrm{keV}$. It was also $52.87 \pm 22.86 \mathrm{HU}$ before using and $52.54 \pm 23.96 \mathrm{HU}$ after using in $80 \mathrm{keV}$. There was no significant difference statistically $(\mathrm{p}>0.05)$. In the case of $\mathrm{E}$ rod (trabecular bone), the CT number was measured as $287.64 \pm 51.57 \mathrm{HU}$ before using the MAR algorithm and $290.97 \pm 46.67 \mathrm{HU}$ after using it in $60 \mathrm{keV}$. It was also $194.85 \pm 40.98 \mathrm{HU}$ before using and 197.9 $\pm 37.00 \mathrm{HU}$ after using in $80 \mathrm{keV}$. There was no significant difference statistically $(p>0.05)$. In the case of $F$ 
Table 1. Computer tomography number and standard deviation before and after using metal artifact reduction algorithm by materials.

\begin{tabular}{|c|c|c|c|c|c|c|}
\hline \multirow{2}{*}{ Division } & \multirow{2}{*}{$\mathrm{keV}$} & \multicolumn{2}{|c|}{ Dual CT } & \multicolumn{2}{|c|}{ Single CT } & \multirow{2}{*}{$\mathrm{P}$} \\
\hline & & Ct number & SD & $\mathrm{Ct}$ number & SD & \\
\hline \multirow{5}{*}{$\begin{array}{c}\text { A } \\
\text { Adipose } \\
0.96\end{array}$} & $60 \mathrm{keV}$ & -64.34 & 20.45 & -63.62 & 18.25 & \multirow{5}{*}{$\mathrm{P}>0.05$} \\
\hline & $65 \mathrm{keV}$ & -56.16 & 16.52 & -55.74 & 14.25 & \\
\hline & $70 \mathrm{keV}$ & -50.16 & 16.74 & -50.94 & 12.73 & \\
\hline & $75 \mathrm{keV}$ & -45.31 & 18.26 & -46.74 & 14.45 & \\
\hline & $80 \mathrm{keV}$ & -41.82 & 19.4 & -43.72 & 17.13 & \\
\hline \multirow{5}{*}{$\begin{array}{c}\text { B } \\
\text { Breast50/500.99 }\end{array}$} & $60 \mathrm{keV}$ & -39.92 & 17.79 & -31.37 & 18.25 & \multirow{5}{*}{$\mathrm{P}>0.05$} \\
\hline & $65 \mathrm{keV}$ & -34.65 & 14.45 & -33.23 & 15.45 & \\
\hline & $70 \mathrm{keV}$ & -31.21 & 14.45 & -31.27 & 15.57 & \\
\hline & $75 \mathrm{keV}$ & -28.47 & 16.2 & -27.27 & 16.68 & \\
\hline & $80 \mathrm{keV}$ & -26.5 & 17.55 & -27.11 & 18.37 & \\
\hline \multirow{5}{*}{$\begin{array}{c}\text { C } \\
\text { Lung } \\
\text { (Exhale) }\end{array}$} & $60 \mathrm{keV}$ & -461.44 & 95.19 & -488.37 & 4.53 & \multirow{5}{*}{$\mathrm{P}>0.05$} \\
\hline & $65 \mathrm{keV}$ & -461.51 & 93.44 & -435.38 & 44.35 & \\
\hline & $70 \mathrm{keV}$ & -463.33 & 93.31 & -462.78 & 46.77 & \\
\hline & $75 \mathrm{keV}$ & -464.78 & 93.45 & -481.14 & 46.78 & \\
\hline & $80 \mathrm{keV}$ & -465.9 & 93.72 & -481.22 & 47.11 & \\
\hline \multirow{5}{*}{$\begin{array}{c}\mathrm{D} \\
\text { Liver } \\
1.07\end{array}$} & $60 \mathrm{keV}$ & 51.34 & 23.82 & 50.84 & 26.21 & \multirow{5}{*}{$\mathrm{P}>0.05$} \\
\hline & $65 \mathrm{keV}$ & 50.44 & 20.42 & 50.89 & 22.1 & \\
\hline & $70 \mathrm{keV}$ & 51.41 & 20.53 & 51.55 & 22.45 & \\
\hline & $75 \mathrm{keV}$ & 52.19 & 21.84 & 52.65 & 23.22 & \\
\hline & $80 \mathrm{keV}$ & 52.87 & 22.86 & 52.75 & 23.47 & \\
\hline \multirow{5}{*}{$\begin{array}{c}\mathrm{E} \\
\text { Trabecular Bone } 200 \mathrm{mg} / \\
\text { ccHA1.16 }\end{array}$} & $60 \mathrm{keV}$ & 287.64 & 51.57 & 296.92 & 46.71 & \multirow{5}{*}{$\mathrm{P}>0.05$} \\
\hline & $65 \mathrm{keV}$ & 254.03 & 46.08 & 257.27 & 41.21 & \\
\hline & $70 \mathrm{keV}$ & 229.68 & 43.55 & 232.26 & 39.35 & \\
\hline & $75 \mathrm{keV}$ & 210.11 & 42.09 & 213.74 & 37.74 & \\
\hline & $80 \mathrm{keV}$ & 194.85 & 40.98 & 197.65 & 37.37 & \\
\hline \multirow{5}{*}{$\begin{array}{c}\mathrm{F} \\
\text { muscle } \\
1.06\end{array}$} & $60 \mathrm{keV}$ & 35.92 & 38.68 & 39.35 & 40.12 & \multirow{5}{*}{$\mathrm{P}>0.05$} \\
\hline & $65 \mathrm{keV}$ & 36.26 & 33.45 & 37.24 & 34.32 & \\
\hline & $70 \mathrm{keV}$ & 37.83 & 33.87 & 39.53 & 34.77 & \\
\hline & $75 \mathrm{keV}$ & 39.09 & 35.42 & 39.24 & 35.21 & \\
\hline & $80 \mathrm{keV}$ & 40.17 & 36.75 & 40.74 & 36.47 & \\
\hline \multirow{5}{*}{$\begin{array}{c}\mathrm{G} \\
\text { Adipose } \\
0.96\end{array}$} & $60 \mathrm{keV}$ & -59.57 & 25.6 & -63.2 & 21.65 & \multirow{5}{*}{$\mathrm{P}<0.05$} \\
\hline & $65 \mathrm{keV}$ & -52.21 & 20.98 & -55.52 & 17.3 & \\
\hline & $70 \mathrm{keV}$ & -47.49 & 20.73 & -49.42 & 16.32 & \\
\hline & $75 \mathrm{keV}$ & -43.7 & 22.53 & -45.22 & 19.37 & \\
\hline & $80 \mathrm{keV}$ & -40.94 & 23.99 & -41.54 & 21.32 & \\
\hline \multirow{5}{*}{$\begin{array}{c}\mathrm{H} \\
\text { Lung } \\
\text { (inhale) }\end{array}$} & $60 \mathrm{keV}$ & -731.98 & 83.19 & -737.88 & 63.74 & \multirow{5}{*}{$\mathrm{P}>0.05$} \\
\hline & $65 \mathrm{keV}$ & -732.06 & 82.54 & -737.52 & 61.2 & \\
\hline & $70 \mathrm{keV}$ & -733.97 & 82.42 & -739.79 & 61.78 & \\
\hline & $75 \mathrm{keV}$ & -735.49 & 82.67 & -741.28 & 61.46 & \\
\hline & $80 \mathrm{keV}$ & -736.58 & 82.96 & -740.14 & 61.47 & \\
\hline \multirow{5}{*}{$\begin{array}{c}\mathrm{I} \\
\text { Dense Bone } 800 \mathrm{mg} / \\
\text { ccHA1.53 } \\
\text { Liver } \\
1.07\end{array}$} & $60 \mathrm{keV}$ & 129.77 & 308.4 & 131.24 & 310.91 & \\
\hline & $65 \mathrm{keV}$ & 114.61 & 272.85 & 116.45 & 274.26 & \\
\hline & $70 \mathrm{keV}$ & 103.03 & 247.46 & 104.75 & 249.27 & $\mathrm{P}>0.05$ \\
\hline & $75 \mathrm{keV}$ & 93.68 & 227.11 & 95.33 & 228.31 & \\
\hline & $80 \mathrm{keV}$ & 86.2 & 211.15 & 86.12 & 212.24 & \\
\hline
\end{tabular}


Table 1. Continued.

\begin{tabular}{|c|c|c|c|c|c|c|}
\hline \multirow{2}{*}{ Division } & \multirow{2}{*}{$\mathrm{keV}$} & \multicolumn{2}{|c|}{ Dual CT } & \multicolumn{2}{|c|}{ Single CT } & \multirow{2}{*}{$\mathrm{P}$} \\
\hline & & Ct number & SD & $\mathrm{Ct}$ number & SD & \\
\hline \multirow{5}{*}{$\begin{array}{c}\mathrm{J} \\
\text { Liver } \\
1.07\end{array}$} & $60 \mathrm{keV}$ & 58.89 & 24.79 & 61.35 & 25.23 & \multirow{5}{*}{$\mathrm{P}>0.05$} \\
\hline & $65 \mathrm{keV}$ & 55.51 & 21.22 & 56.42 & 21.36 & \\
\hline & $70 \mathrm{keV}$ & 54.45 & 20.85 & 57.74 & 20.74 & \\
\hline & $75 \mathrm{keV}$ & 53.6 & 22.68 & 56.55 & 21.22 & \\
\hline & $80 \mathrm{keV}$ & 53.18 & 24.22 & 56.41 & 22.17 & \\
\hline \multirow{5}{*}{$\begin{array}{c}\mathrm{K} \\
\text { Dense Bone } 800 \mathrm{mg} / \\
\text { ccHA1.53 }\end{array}$} & $60 \mathrm{keV}$ & 115.02 & 298.97 & 112.34 & 298.24 & \multirow{5}{*}{$\mathrm{P}>0.05$} \\
\hline & $65 \mathrm{keV}$ & 102.61 & 265.78 & 100.24 & 265.34 & \\
\hline & $70 \mathrm{keV}$ & 93.11 & 242.45 & 90.83 & 242.33 & \\
\hline & $75 \mathrm{keV}$ & 85.47 & 223.8 & 83.26 & 224.37 & \\
\hline & $80 \mathrm{keV}$ & 79.38 & 209.2 & 78.24 & 209.27 & \\
\hline \multirow{5}{*}{$\begin{array}{c}\mathrm{L} \\
\text { muscle } \\
1.06\end{array}$} & $60 \mathrm{keV}$ & 45.71 & 23.2 & 43.99 & 23.24 & \multirow{5}{*}{$\mathrm{P}>0.05$} \\
\hline & $65 \mathrm{keV}$ & 44.52 & 19.83 & 42.31 & 20.36 & \\
\hline & $70 \mathrm{keV}$ & 45.32 & 19.29 & 43.24 & 19.54 & \\
\hline & $75 \mathrm{keV}$ & 46.01 & 20.78 & 43.48 & 20.57 & \\
\hline & $80 \mathrm{keV}$ & 46.66 & 22.1 & 44.04 & 21.5 & \\
\hline \multirow{5}{*}{$\begin{array}{c}\text { M } \\
\text { Lung } \\
\text { (inhale) }\end{array}$} & $60 \mathrm{keV}$ & -723.58 & 74.82 & -711.92 & 114.27 & \multirow{5}{*}{$\mathrm{P}<0.05$} \\
\hline & $65 \mathrm{keV}$ & -725.35 & 73.47 & -711.22 & 116.31 & \\
\hline & $70 \mathrm{keV}$ & -728.57 & 73.53 & -711.2 & 117.45 & \\
\hline & $75 \mathrm{keV}$ & -731.14 & 73.97 & 717.64 & 119.78 & \\
\hline & $80 \mathrm{keV}$ & -733.06 & 74.47 & -718.4 & 119.77 & \\
\hline \multirow{5}{*}{$\begin{array}{c}\text { C } \\
\text { Trabecular Bone } 200 \mathrm{mg} / \\
\text { ccHA1.16 }\end{array}$} & $60 \mathrm{keV}$ & 292.06 & 43.62 & 288.3 & 50.21 & \multirow{5}{*}{$\mathrm{P}>0.05$} \\
\hline & $65 \mathrm{keV}$ & 258.67 & 38.59 & 254.73 & 43.74 & \\
\hline & $70 \mathrm{keV}$ & 234.57 & 35.59 & 232.31 & 40.78 & \\
\hline & $75 \mathrm{keV}$ & 215.24 & 34.76 & 221.5 & 39.45 & \\
\hline & $80 \mathrm{keV}$ & 200.11 & 34.39 & 199.72 & 38.44 & \\
\hline \multirow{5}{*}{$\begin{array}{c}\text { O } \\
\text { Breast 50/500.99 }\end{array}$} & $60 \mathrm{keV}$ & -39.15 & 22.96 & -37.42 & 23.55 & \multirow{5}{*}{$\mathrm{P}>0.05$} \\
\hline & $65 \mathrm{keV}$ & -34.47 & 18.84 & -32.75 & 19.24 & \\
\hline & $70 \mathrm{keV}$ & -31.12 & 18.42 & -25.57 & 18.71 & \\
\hline & $75 \mathrm{keV}$ & -28.45 & 20.53 & -27.3 & 20.77 & \\
\hline & $80 \mathrm{keV}$ & -26.5 & 22.3 & -27.7 & 22.2 & \\
\hline \multirow{5}{*}{$\begin{array}{c}\mathrm{P} \\
\text { Lung (Exhale) }\end{array}$} & $60 \mathrm{keV}$ & -461.81 & 84.95 & -436.34 & 49.32 & \multirow{5}{*}{$\mathrm{P}<0.05$} \\
\hline & $65 \mathrm{keV}$ & -462.71 & 83.25 & -474.7 & 49.33 & \\
\hline & $70 \mathrm{keV}$ & -465.28 & 83.36 & -474.13 & 49.75 & \\
\hline & $75 \mathrm{keV}$ & -467.33 & 83.78 & -474.2 & 50.63 & \\
\hline & $80 \mathrm{keV}$ & -468.93 & 84.21 & -475.23 & 50.62 & \\
\hline \multirow{5}{*}{$\begin{array}{c}\mathrm{Q} \\
\mathrm{H} 2 \mathrm{O} 1.01\end{array}$} & $60 \mathrm{keV}$ & 0 & 0 & 0 & 0 & \multirow{5}{*}{$\mathrm{P}>0.05$} \\
\hline & $65 \mathrm{keV}$ & 0 & 0 & 0 & 0 & \\
\hline & $70 \mathrm{keV}$ & 0 & 0 & 0 & 0 & \\
\hline & $75 \mathrm{keV}$ & 0 & 0 & 0 & 0 & \\
\hline & $80 \mathrm{keV}$ & 0 & 0 & 0 & 0 & \\
\hline
\end{tabular}

rod (muscle), the $\mathrm{CT}$ number was measured as $35.92 \pm$ 38.68 HU before using the MAR algorithm and $39.35 \pm$ $40.55 \mathrm{HU}$ after using it in $60 \mathrm{keV}$. It was also $40.17 \pm$ $36.75 \mathrm{HU}$ before using and $40.48 \pm 36.52 \mathrm{HU}$ after using in $80 \mathrm{keV}$. There was no significant difference statistically $(p>0.05)$.
In the case of I rod (dense bone), the CT number was measured as $129.77 \pm 308.40 \mathrm{HU}$ before using the MAR algorithm and $131.33 \pm 310.90 \mathrm{HU}$ after using it in 60 $\mathrm{keV}$. It was also $86.20 \pm 211.15 \mathrm{HU}$ before using and $87.96 \pm 212.21 \mathrm{HU}$ after using in $80 \mathrm{keV}$. There was no significant difference statistically $(p>0.05)$. For $M$ rod 

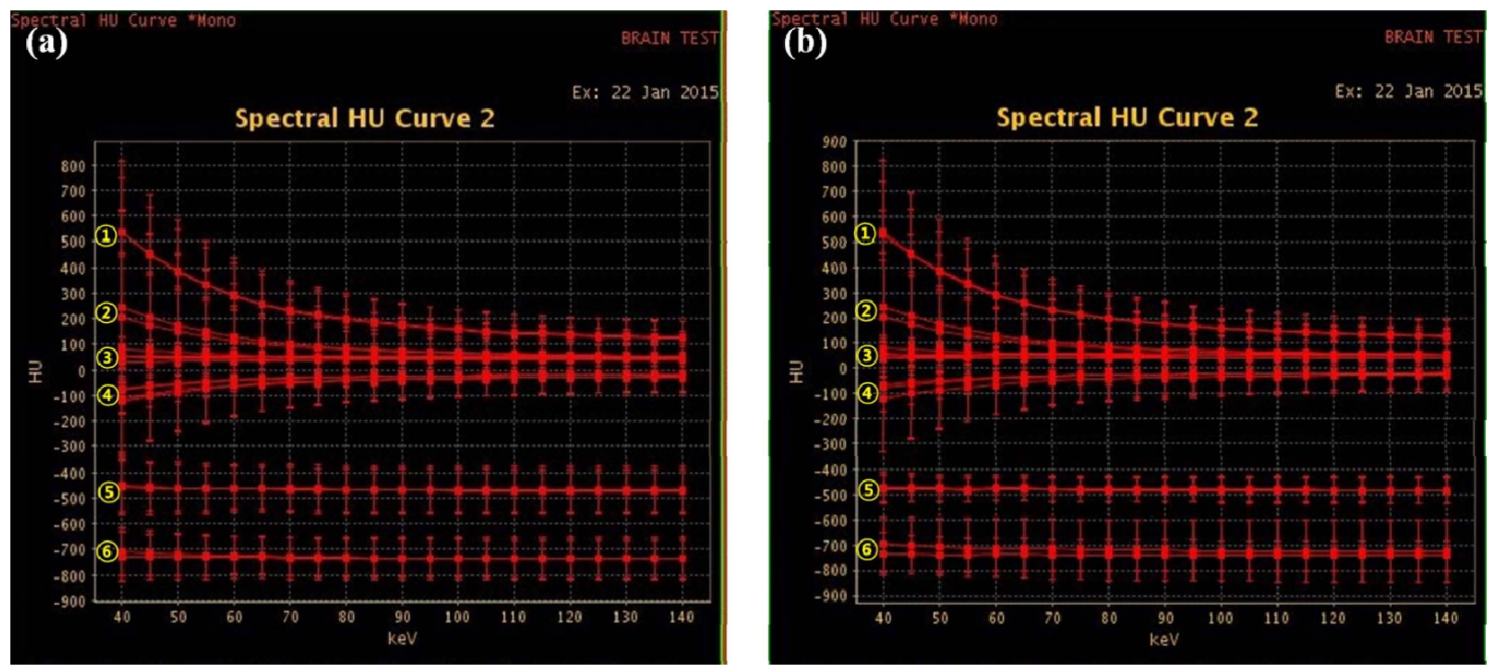

Fig. 4. (Color online) Spectral HU curve before (A) and after using MAR algorithm

1. $\mathrm{N}$ rod (Trabecular Bone), E rod (Trabecular Bone)

2. I rod (Dense Bone), $\mathrm{K}$ rod (Dense Bone)

3. $\mathrm{J}$ rod (Liver), D rod (Liver), L rod (muscle), $\mathrm{F}$ rod (muscle)

4. A rod (Adipose), G rod (Adipose), B rod (Breast), O rod (Breast)

5. $\mathrm{C}$ rod (Lung (Exhale)), $\mathrm{P}$ rod (Lung (Exhale)), $\mathrm{M}$ rod (Lung (inhale)), $\mathrm{H}$ rod (Lung (Exhale))

(lung (inhale)), the CT number was measured as -723.58 $\pm 74.82 \mathrm{HU}$ before using the MAR algorithm and -710.94 $\pm 114.54 \mathrm{HU}$ after using it in $60 \mathrm{keV}$. It was also -733.06 $\pm 74.47 \mathrm{HU}$ before using and $-719.47 \pm 119.84 \mathrm{HU}$ after using in $80 \mathrm{keV}$. Conclusively, $\mathrm{M}$ rod (lung (inhale)) showed that the CT numbers were reduced more after using the MAR algorithm than before using, and its noise was increased as well $(\mathrm{p}<0.05)$. According to the spectral HU curve, each material both before and after using the MAR algorithm was analyzed around its inherent CT values (Fig. 4). In the cases of $\mathrm{N}$ rod (trabecular bone) and $\mathrm{E}$ rod (trabecular bone), the CT numbers decreased as $\mathrm{keV}$ increased but were constant above $90 \mathrm{keV}$. The CT numbers from $40 \mathrm{keV}$ to $140 \mathrm{keV}$ were consistent in cases of $\mathrm{J}$ rod (liver), D rod (liver), L rod (muscle) and $\mathrm{F}$ rod (muscle). For A rod (adipose), G rod (adipose), B rod (breast) and $\mathrm{O}$ rod (breast), the CT numbers increased as $\mathrm{keV}$ increased but were constant above $90 \mathrm{keV}$. The CT numbers from $40 \mathrm{keV}$ to $140 \mathrm{keV}$ were consistent in the cases of $\mathrm{C}$ rod (lung (exhale)), $\mathrm{P}$ rod (lung (exhale)), $\mathrm{M}$ rod (lung (inhale)), and $\mathrm{H}$ rod (lung (exhale)).

\section{Discussions}

The ultimate purpose of the CT test is to provide a high-definition image that can be used for accurate diagnosis, with minimum radiation and while causing minimum inconvenience to the patient. If the latest equip- ment is not associated with the material or the technique that plays additional function to realize images in every test, it won't express the images what we desire. The existing method helps too much that we provide appropriate images. However, it is true that more effective images are required to provide for disease decoding. Dual CT was recently developed. This method uses the theory that Table can be categorized due to the differential attenuation generating two different X-rays (at $80 \mathrm{kV}$ and $140 \mathrm{kV}$, or $100 \mathrm{kV}$ and $140 \mathrm{kV}$ ) from the specific material [13-15]. Because it can analyze material ingredients, dual $\mathrm{CT}$ is usually used in various clinical trials. The contrast enhancement of tumors in the kidney area is evaluated by dual CT through categorizing calcium stones and uric acid stones, or distinguishing iodine, which is a primary ingredient of the contrast medium [16-22]. Like this, dual CT diagnosed through the material analysis but couldn't complete for various materials. Therefore, this study analyzed the characteristics of materials using a phantom having various elements of human tissues, and compared single CT and its image quality. As a result, the CT numbers were diversely distributed but the image quality was no different with single CT. Generally, each pixel in a CT image has CT numbers indicating the density and is expressed as the linear attenuation coefficient, which is proportional to an attenuated X-ray within the volumes of materials. The CT number is a relatively setting value and is proportional to $\mathrm{X}$-ray attenuation, with $-1,000$ repre- 
senting air, 0 for pure water at $25^{\circ} \mathrm{C}$, and $\pm 1,000$ for compact bone, so the information of materials can be obtained using CT numbers. Because CT images consist of $\mathrm{CT}$ numbers, the changes to $\mathrm{CT}$ numbers between dual $\mathrm{CT}$ and single CT methods were not different, and their image qualities had no differences as well. According to the result of GSI, which was applied to the CT scan in this study, the high ratio of water ingredient didn't affect CT values, even when increasing the energy from 90 $\mathrm{KeV}$, and its changes for the air were not observed at all. The material analysis by energy was possible by applying GSI through this experiment. Conclusively, dual CT is able to obtain various images and perform the characterization analysis of materials only by a scan that maintains the quality of single CT images, so that it will substitute various diagnostic equipments in the future.

\section{Conclusion}

The ingredients of various materials for $\mathrm{CT}$ test were analyzed by various methods in this study, and all these materials had their own atomic numbers, linear absorption coefficients, and CT values. The author could accurately confirm the ingredients and the characteristics of each material within the phantom through the experiment, and could observe its changes according to different energies. For most materials, the $\mathrm{CT}$ values were reduced by increasing the energy. In other words, the CT values were reduced in inverse proportion to the energy in all materials, except for air. In addition, the dual CT method can obtain images of various tube voltages with the same quality as a single CT only through one scan. Conclusively, because dual CT exhibits no changes in image quality and is able to analyze materials by measuring the $\mathrm{CT}$ values of various materials, it will be used in the future as a useful tool in the diagnosis of lesions.

\section{Acknowledgement}

Ki-Youl Kim and Hae-Kag Lee equally contributed to this work. They are co-first authors. "This work was supported in part by the Soonchunhyang University Research Fund".

\section{References}

[1] L. Sibille, F. B. Bouallegue, A. Bourdon, and D. Mariano-Goulart, J. Nucl. Cardiol. 18, 642 (2011).
[2] G. J. Webster, C. G. Rowbottom, and R. I. Mackay, Radiother Oncol. 93, 553 (2009).

[3] U. Schneider, E. Pedroni, and A. Lomax, Phys. Med. Biol. 41, 111 (1996).

[4] Y. Kim, W. A. Tome, and M. Bal, Radiother Oncol. 79, 198 (2006).

[5] W. A. Kalender, R. Hebel, and J. Ebersberger, Radiol. 164, 576 (1987).

[6] D. D. Robertson, P. J. Weiss, E. K. Fishman, D. Magid, and P. S. Walker. J. Compute. Assist. Tomogr. 12, 236 (1988).

[7] D. D. Robertson, J. Yuan, G. Wang, and W. M. Vannier, and: J. Comput. Assist. Tomogr. 21, 293 (1997).

[8] G. Hilgers, T. Nuver, and A. Minken, J. Appl. Clin. Med. Phys. 15, 4597 (2014).

[9] G. Wang, T. Feri, and M. W. Vannier, Acad. Radiol. 7, 607 (2000).

[10] S. Zhao. D. D. Robertson, G. Wang, B. Whiting, and K. T. Bae, IEEE Trans. Med. Imaging. 19, 1238 (2000).

[11] A. Kawamata, Y. Ariji, and R. P. Langlais, Dent. Clin. North. Am. 44, 395 (2000).

[12] D. Dabirrahmani, J. Magnussen, and R. C. Appleyard, J. Comput. Assist. Tomogr. 39, 925 (2015).

[13] T. G. Flohr, H. Bruder, K. Stierstorfer, M. Petersilka, B. Schmidt, and C. H. McCollough, Med. Phys. 35, 5882 (2008).

[14] M. Petersilka, H. Bruder, B. Krauss, K. Stierstorfer, and T. G. Flohr, Technical principles of dual source CT. Eur. J. Radiol. 68, 362 (2008).

[15] T. R. Johnson, B. Krauss, M. Sedlmair, M. Grasruck, H. Bruder, D. Morhard, C. Fink, S. Weckbach, M. Lenhard, B. Schmidt, T. Flohr, M. F. Reiser, and C. R. Becker, Eur. Radiol. 17, 1510 (2007).

[16] A. Graser, T. R. Johnson, M. Bader, M. Staehler, N. Haseke, K. Nikolaou, M. F. Reiser, C. G. Stief, and Becker CR, Invest. Radiol. 43, 112 (2008).

[17] A. Graser, T. R. Johnson, E. M. Hecht, C. R. Becker, C. Leidecker, M. Staehler, C. G. Stief, H. Hildebrandt, M. C. Godoy, M. E. Finn, F. Stepansky, M. F. Reiser, and M. Macari, Radiology. 252, 433 (2009).

[18] M. Periyasamy and R. Dhanasekaran, J. Magn. 20, 295 (2015).

[19] M. S. Kim, K. S. Park, and J. H. Cho, J. Magn. 19, 261 (2015).

[20] Y. C. Heo, H. K. Lee, C. S. Park, and J. H. Cho, J. Magn. 20, 40 (2015).

[21] J. H. Lee, H. K. Lee, J. H. Cho, and M. J. Cheon, J. Magn. 19, 372 (2014).

[22] J. H. Cho, J. H. Lee, C. S. Park, S. Y. Lee, J. Lee, D. H. Moon, and H. K. Lee, J. Magn. 19, 248 (2014). 